\title{
Teste da ação antibacteriana in vitro de óleo essencial comercial de Origanum vulgare (orégano) diante das cepas de Escherichia coli e Staphylococcus aureus
}

\author{
In vitro antibacterial activity of Origanum vulgare (oregano) essential oil \\ against Escherichia coli and Staphylococcus aureus strains
}

\author{
Márcio Martins de Araujo ${ }^{*}$, Priscila Larcher Longo ${ }^{2}$

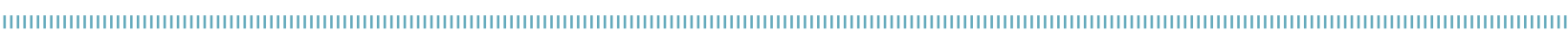

RESUMO: Origanum vulgare (orégano) tem sido reconhecido como uma espécie vegetal que possui várias propriedades terapêuticas, de modo que atualmente seu potencial antimicrobiano vem recebendo um grande interesse científico. Este estudo objetivou avaliar a ação antimicrobiana (bactericida e bacteriostática) do óleo essencial comercial de O. vulgare sobre cepas de Escherichia coli e Staphylococcus aureus, bactérias envolvidas em toxinfecçóes alimentares. Foram utilizadas cepas padrão (American Type Culture Collection - ATCC) e clínicas e estas foram submetidas à ação do óleo essencial em diferentes concentrações, por meio das técnicas de microdiluição (para determinação da concentração inibitória mínima - CIM) e de macrodiluição (para determinação da concentração bactericida mínima-CBM). Foi possível observar que houve variaçáo do potencial antimicrobiano do óleo essencial entre as cepas utilizadas. Para E. coli ATCC 25922, a CIM foi de $6,25 \mu \mathrm{L} / \mathrm{mL}$ e a CBM de $12,5 \mu \mathrm{L} / \mathrm{mL}$, enquanto para a amostra clínica os valores foram 12,5 e $25 \mu \mathrm{L} / \mathrm{mL}$, respectivamente. Já para $S$. aureus ATCC 25923, a CIM e a CBM foram de $12,5 \mu \mathrm{L} / \mathrm{mL}$, enquanto para a amostra clínica os valores foram 6,25 e $25 \mu \mathrm{L} / \mathrm{mL}$, respectivamente. Portanto, esse óleo essencial de $O$. vulgare mostrou poder de inibição do crescimento e viabilidade das cepas ensaiadas. No entanto, novos estudos são necessários para que sejam determinadas as concentraçóes ideais do orégano como antimicrobiano natural, levando em consideração os fatores que influenciam sua composição e a quantidade e qualidade dos compostos ativos.

PALAVRAS-CHAVE: atividade antimicrobiana; orégano; óleo essencial; Escherichia coli; Staphylococcus aureus.

\begin{abstract}
Origanum vulgare (oregano) was recognized as a species with several therapeutic properties. Nowadays, its antimicrobial potential has been receiving a large scientific interest. This study aimed at evaluating the antimicrobial activity (bactericidal and bacteriostatic) of an $O$. vulgare commercial essential oil against strains of Escherichia coli and Staphylococcus aureus bacteria related to food intoxication and infection. Standard (American Type Culture Collection - ATCC) and clinical strains were submitted to the action of an essential oil in different concentrations through microdilution (for determination of minimum inhibitory concentration - MIC) and macrodilution (for determination of the minimum bactericidal concentration MBC) techniques. Variation in the antimicrobial potential of an essential oil among the tested strains was observed. For E. coli ATCC 25922, the MIC was $6.25 \mu \mathrm{L} / \mathrm{mL}$ and MBC $12.5 \mu \mathrm{L} / \mathrm{mL}$, while for the clinical sample, values varied respectively between 12.5 and $25 \mu \mathrm{L} / \mathrm{mL}$. For $S$. aureus ATCC 25923 , values of MIC and $\mathrm{MBC}$ were $12.5 \mu \mathrm{L} / \mathrm{mL}$, while for the clinical sample they respectively were 6.25 and $25 \mu \mathrm{L} / \mathrm{mL}$. Thus, the essential oil of $O$. vulgare showed inhibition power of growth and viability in the tested strains. However, further studies are necessary to determine the optimal concentrations of oregano to act as a natural antimicrobial, considering the factors that influence their composition, and the quantity and quality of active compounds.
\end{abstract}

KEYWORDS: antimicrobial activity; oregano; essential oil; Escherichia coli; Staphylococcus aureus.

\footnotetext{
${ }^{1}$ Centro de Biotecnologia, Instituto de Pesquisas Energéticas e Nucleares, Universidade de São Paulo (USP) - São Paulo (SP), Brasil. ${ }^{2}$ Departamento de Medicina, Faculdade das Américas (FAM) - São Paulo (SP), Brasil.

*Autor correspondente: marcio.mda@hotmail.com

Recebido em: 18/08/2014. Aceito em: 12/04/2016
} 


\section{INTRODUÇÃO}

Entre as espécies bacterianas com maior importância etiológica em processos tóxicos e infecciosos humanos destacam-se Staphylococcus aureus e Escherichia coli (LEvy et al., 2004).

$S$. aureus apresenta-se como um coco Gram-positivo, que pertence à família Micrococacceae, imóvel, medindo de 0,5 a $1,0 \mu \mathrm{m}$ e agrupando-se em massas irregulares que lembram cachos de uvas. São anaeróbios facultativos, mesófilos, com temperatura ótima de crescimento em torno de $30^{\circ}$ a $37^{\circ} \mathrm{C}$. Algumas fontes de infecçóes podem ser endógenas, providas do próprio indivíduo, como em casos de infecçóes em pacientes imunocomprometidos, ou de fontes exógenas, sendo esta segunda caracterizada por fatores associados ao meio, tais como agressóes, contato físico direto, objetos contaminados, fluidos contaminados e vias aéreas (Vieira; Agostini, 2011).

Essa espécie bacteriana produz toxinas termoestáveis que podem permanecer no alimento mesmo após o cozimento. Dentre as intoxicaçóes alimentares de origem bacteriana no mundo, cerca de $45 \%$ estão relacionadas a $S$. aureus. Após um curto período de incubaçáo, de uma a seis horas após a ingestáo do alimento contaminado, essas intoxicaçóes são caracterizadas por náuseas, vômitos, dores abdominais e diarreia (Bresolin et al., 2005).

Já $E$. coli é um bacilo Gram-negativo, pertence à família das Enterobacteriaceae, possui motilidade por meio de flagelos ou é imóvel, apresenta cerca de $2 \mu \mathrm{m}$ de comprimento e $0,5 \mu \mathrm{m}$ de diâmetro. Essas bactérias utilizam D-glicose e outros carboidratos para obter energia e formam ácido e gás como produtos metabólicos. A espécie, presente na microbiota intestinal de animais de sangue quente, está inserida no grupo dos coliformes fecais (CunHa, 2006).

Sua habilidade na produção de doenças está associada à diversidade antigênica relacionada a elementos estruturais (Lipopolissacarídeo - LPS, cápsula), à adesão (adesinas) e à invasão (exotoxinas). A espécie está associada a infecçóes no trato urinário, sepse, meningites neonatais e gastrenterites e pode ser subdividida em cinco grupos patogênicos principais: E. coli enteropatogênica (EPEC), E. coli enterotoxigênica (ETEC), E. coli entero-hemorrágica (EHEC), E. coli enteroinvasiva (EIEC) e E. coli enteroagregativa (EAEC) (PrèrE; FAyet, 2005; Shelton et al., 2006).

A resistência antimicrobiana é o desenvolvimento de resistência em micro-organismos (bactérias, vírus, parasitas e fungos) a um medicamento antimicrobiano ao qual eram previamente sensíveis. Essa resistência em uma ampla variedade de agentes infecciosos é uma ameaça crescente à saúde pública, especialmente pela rápida disseminação mundial de bactérias multirresistentes que causam infecçôes comuns e resistem ao tratamento com medicamentos existentes (WHo, 2015).

As bactérias podem conter genes que codificam a produção de enzimas com propriedades de clivar ou promover alteraçóes estruturais na molécula, como as betalactamases. Estas atuam promovendo a hidrólise dos derivados betalactâmicos, fazendo com que a configuração molecular do antibiótico seja incapaz de se ligar ao seu sítio receptor, as penicillin binding proteins (PBPs), impossibilitando o medicamento de inibir a síntese da parede celular bacteriana; dessa forma, a bactéria continua seu ciclo reprodutivo normalmente (Fio et al., 2000).

A Organização Mundial de Saúde (WHo, 2015), após avaliar seis regióes mundiais, revelou que $E$. coli apresenta resistência às cefalosporinas de terceira geração e às fluoroquinolonas (tratamento de infecçóes no trato urinário), enquanto S. aureus demonstrou resistência à meticilina (antibiótico betalactâmico do grupo da penicilina), sendo $80 \%$ dos casos na região Africana e do Pacífico Ocidental, 90\% na região Americana, 50\% na região do Mediterrâneo Oriental, 60\% na região Europeia e 25\% na região Sudeste da Ásia. Isso significa que o tratamento com antibióticos padróes não está funcionando, o que aumenta o risco de morte e o custo dos cuidados de saúde com estadas mais longas no hospital e cuidados mais intensivos necessários.

A medicina alternativa vem buscando meios naturais para o tratamento de infecçóes causadas por essas e outras bactérias resistentes. Nesse contexto da sociedade moderna, é crescente o interesse pelo uso terapêutico de produtos naturais, especificamente aqueles derivados de plantas (Oliveira et al., 2007).

As plantas são conhecidas por produzirem uma grande variedade de pequenas moléculas antibióticas, geralmente classificadas como fitoalexinas. Sua natureza estrutural é diversa, sendo os terpenoides, os glicosídeos, os flavonoides e os polifenóis os principais componentes. De modo interessante, a maioria dessas pequenas moléculas tem atividade antibiótica fraca - várias ordens de grandeza menor que aquelas de antibióticos comuns produzidos por bactérias ou fungos. Porém, apesar do fato de antibacterianos derivados de plantas serem menos potentes, as plantas combatem infecçóes com sucesso. Portanto, torna-se claro que elas adotaram um paradigma diferente, de sinergismo, para combater as infecçóes. Esse efeito sinérgico explica a superioridade terapêutica de muitos extratos de plantas derivados da medicina tradicional, quando comparados com seus respectivos constituintes isolados (MagalHâEs, 2010).

De acordo com Oliveira et al. (2008), o óleo essencial de O. vulgare apresenta composição variável de compostos ativos, sendo que os fenóis, como carvacrol e timol, podem alcançar entre 80,2 e $98 \%$ da composição total do óleo. Esses compostos fenólicos exercem atividade antimicrobiana, lesando as membranas plasmáticas lipídicas, comprometendo a homeostase do pH e o equilíbrio de íons orgânicos, impedindo a divisão celular e causando desidratação nas células bacterianas.

Assim, em função do potencial da especiaria $O$. vulgare em inibir o crescimento microbiano (Alexopoulos et al., 2011; SAntos et al., 2011), este estudo testou o potencial antimicrobiano do óleo essencial da especiaria em cepas de micro-organismos deteriorantes de alimentos causadores de infecçóes e intoxicaçóes alimentares, E. coli e $S$. aureus. 


\section{MATERIAL E MÉTODOS}

O óleo essencial comercial de orégano, Laszlo $10 \mathrm{~mL}$, obtido por destilaçáo a vapor (método que compreende o uso de várias vidraçarias no laboratório, de acordo com SANTOS et al., 2004), em Minas Gerais, foi adquirido em uma loja virtual (Aromalandia) especializada em produtos naturais.

Para os testes antimicrobianos, foram utilizadas duas cepas de E. coli e duas de $S$. aureus. Cada espécie teve uma amostra padrão American Type Culture Collection (ATCC) (gentilmente cedida pelo Laboratório de Microbiologia Oral do Instituto de Ciências Biomédicas II da Universidade de São Paulo, São Paulo, SP) e uma isolada de amostras de pacientes do Laboratório Cytolab (Mogi das Cruzes, SP) (gentilmente cedida pelo Laboratório de Microbiologia da Universidade Braz Cubas, Mogi das Cruzes, SP). As amostras padrão utilizadas foram ATCC 25922 (E. coli) e ATCC 25923 (S. aureus).

As amostras bacterianas, obtidas de estoques congelados a $-20^{\circ} \mathrm{C}$, foram semeadas em ágar Brain Heart Infusion (BHI) e incubadas em estufa bacteriológica (Fabbe-Primar) a $37^{\circ} \mathrm{C}$ por 24 horas. Após a incubação, foi realizada coloração de Gram para confirmar as características esperadas das amostras e estas foram transferidas para tubos de ensaio contendo $5 \mathrm{~mL}$ de caldo de BHI. Os tubos foram incubados por 24 horas a $37^{\circ} \mathrm{C}$, obtendo-se as "culturas-máe".

Essas culturas tiveram sua turbidez ajustada usando espectrofotômetro (Biorad, Califórnia, EUA) e cubetas apropriadas para determinar a absorbância. $\mathrm{O}$ comprimento de onda utilizado foi $660 \mathrm{~nm}$ e a absorbância foi ajustada para 0,08 a 0,1 Å, que corresponde a 1 a 3 X $10^{8}$ unidades formadoras de colônias (UFC) $/ \mathrm{mL}$ (NCCLS, 2003). As culturas ajustadas foram chamadas de inóculo.

\section{Teste da ação antimicrobiana}

A ação de óleo essencial do orégano sobre as amostras de E coli e $S$. aureus foi testada pelos métodos de macrodiluição e microdiluiçâo em caldo, de acordo com a "Metodologia dos Testes de Sensibilidade a Agentes Antimicrobianos por Diluição para Bactérias de Crescimento Aeróbico", padronizada pelo National Committee for Clinical Laboratory Standards (NCCLS, 2003), com algumas modificaçōes.

$\mathrm{O}$ meio de cultura dos testes foi preparado com caldo de BHI acrescido de polisorbato 80 (Tween 80 ) a $1 \%$ e óleo essencial. A diluiçáo seriada foi realizada em tubos com concentraçôes de 100; 50; 25; 12,5; 6,25; 3,152 e 1,562 $\mu \mathrm{L}$ de óleo por $1 \mathrm{~mL}$ de meio de cultura acrescido de Tween 80 .

\section{Macrodiluição}

Para realizar o teste da macrodiluição e estimar a concentração bactericida mínima, foram adicionados a microtubos $0,9 \mathrm{~mL}$ do meio de cultura com diferentes concentraçóes do óleo de orégano e $0,1 \mathrm{~mL}$ de inóculo bacteriano ajustado das amostras clínicas e padrão (1 a $\left.3 \times 10^{8} \mathrm{UFC} / \mathrm{mL}\right)$.
Como controle positivo, foram utilizados o meio de cultura líquido acrescido de Tween 80 e o inóculo bacteriano; como controle negativo, apenas o meio de cultura acrescido de Tween 80 .

Os testes foram realizados em duplicata e os microtubos foram incubados a $37^{\circ} \mathrm{C}$ por 24 horas. Após o período de incubação, estes foram inspecionados visualmente para evidenciar o crescimento bacteriano, traduzido pela turbidez. Depois da análise visual, coletou-se uma alçada de cada tubo, o material foi semeado em ágar Müeller-Hinton e as placas foram incubadas a $37^{\circ} \mathrm{C}$ por 24 horas (NCCLS, 2003).

Após a semeadura, utilizou-se o método colorimétrico, em que foram adicionados $25 \mu \mathrm{L}$ de resazurina sódica $0,01 \%$ (Polysciences, Inc.), aguardando uma hora para a leitura dos resultados, de acordo com Bonam et al. (2010), momento em que a coloração azul demonstra a inatividade bacteriana e a vermelha, a atividade bacteriana.

Em relaçáo às placas semeadas, após o período de incubação, elas foram inspecionadas para observação do crescimento superficial de colônias bacterianas.

\section{Microdiluição}

A técnica da microdiluiçáo foi realizada para se estimar a concentração inibitória mínima do óleo essencial para as amostras padrão de $E$. coli e $S$. aureus, de acordo com Souza (2006), em triplicata, com algumas modificaçóes.

Após a preparação dos microtubos do experimento da macrodiluição, alíquotas de $180 \mu \mathrm{L}$ de cada tubo foram colocadas em poços de placas com 96 poços (Corning); ainda, foram adicionados os controles positivo e negativo e o caldo BHI sem Tween 80 à placa, para verificar se o Tween tinha algum efeito sobre as bactérias. A placa foi incubada estaticamente a $37^{\circ} \mathrm{C}$ por 24 horas.

Após o período de incubação, o método colorimétrico com resazurina sódica $0,01 \%$ foi utilizado, aplicando-se $10 \mu \mathrm{L}$ da soluçáo em cada poço e esperando-se uma hora para realizar a leitura visual dos resultados, em que o azul caracteriza a inatividade bacteriana e o vermelho, a atividade.

\section{RESULTADOS E DISCUSSÃO}

De acordo com a cromatografia gasosa disponibilizada pela fabricante (Laszlo - Aromaterapia Ltda., Minas Gerais), os principais componentes encontrados na alíquota do óleo essencial de O. vulgare utilizado foram carvacrol $(76,5 \%)$, timol $(4,3 \%)$, p-cimeno $(4 \%), \gamma$-terpineno $(3,2 \%)$, cariofileno $(1,5 \%)$, limoneno $(1,4 \%)$, felandreno $(1,2 \%)$ e canfeno $(1,1 \%)$.

Vale ressaltar que as concentraçôes de diferentes componentes podem variar dependendo do tipo de solo, do clima, das práticas agrícolas, da variedade do orégano e do processo de extração. KoKKINI et al. (1997) verificaram que a composição do orégano Origanum vulgare subsp. hirtum, proveniente de seis 
localidades de três regiôes geográficas distintas na Grécia, apresentaram variaçóes em plantas colhidas no veráo e no outono ( $\gamma$-terpineno variou de 0,6 a 3,6\%; p-cimeno, de 17,3 a 51,3\%; timol, de 0,2 a $42,8 \%$; e carvacrol, de 1,7 a $69,6 \%$ ), sendo que o teor de carvacrol sempre era maior no verão, uma vez que aquele dos compostos fenólicos aumenta na florescência.

Segundo Yin et al. (2012), o carvacrol é um aditivo alimentar seguro que apresenta atividades anti-hepatocarcinogênicas ao inibir o crescimento de células HepG2, induzindo a apoptose pela ativação direta da via mitocondrial.

Já foi mostrado que o carvacrol aumenta a permeabilidade da membrana citoplasmática microbiana, causando uma considerável perda de ATP citoplasmático. Essa ação deve-se a sua capacidade de interagir com a membrana citoplasmática, em que pode se dissolver na bicamada lipídica, alinhando-se entre as cadeias de ácidos graxos. Tal distorçấo da estrutura física poderia causar a expansão e desestabilização da membrana, aumentando sua fluideze resultando no incremento de sua permeabilidade passiva. Acredita-se que sua efetividade esteja relacionada à presença de um grupo hidroxil no anel fenólico que lhe confere alto poder reativo (SouZA, 2006).

SiLVA et al. (2010) reforçaram a importância das interaçóes entre os compostos de baixa concentraçáo, mostrando que a presença de p-cimeno e $\gamma$-terpineno aumenta a ação antimicrobiana de compostos majoritários como o carvacrol e timol, porém o p-cimeno náo tem efeito antibacteriano se usado sozinho, apenas quando combinado, pois ele facilita o transporte do carvacrol por meio da membrana citoplasmática para o interior da célula bacteriana.

No presente estudo, a primeira etapa para avaliação da atividade antimicrobiana do óleo foi realizada pela macrodiluição (Fig. 1). Pode-se observar, a partir dessa técnica, o poder bactericida do óleo essencial de $O$. vulgare em diferentes concentraçōes.
Ainda na macrodiluiçáo, após a semeadura das culturas em placas, foi adicionada a resazurina sódica para evidenciar a atividade microbiana em cada tubo (Fig. 2).A resazurina sódica (7-hidroxi-3H-fenoxazina-3-ona-10-óxido) é um corante que

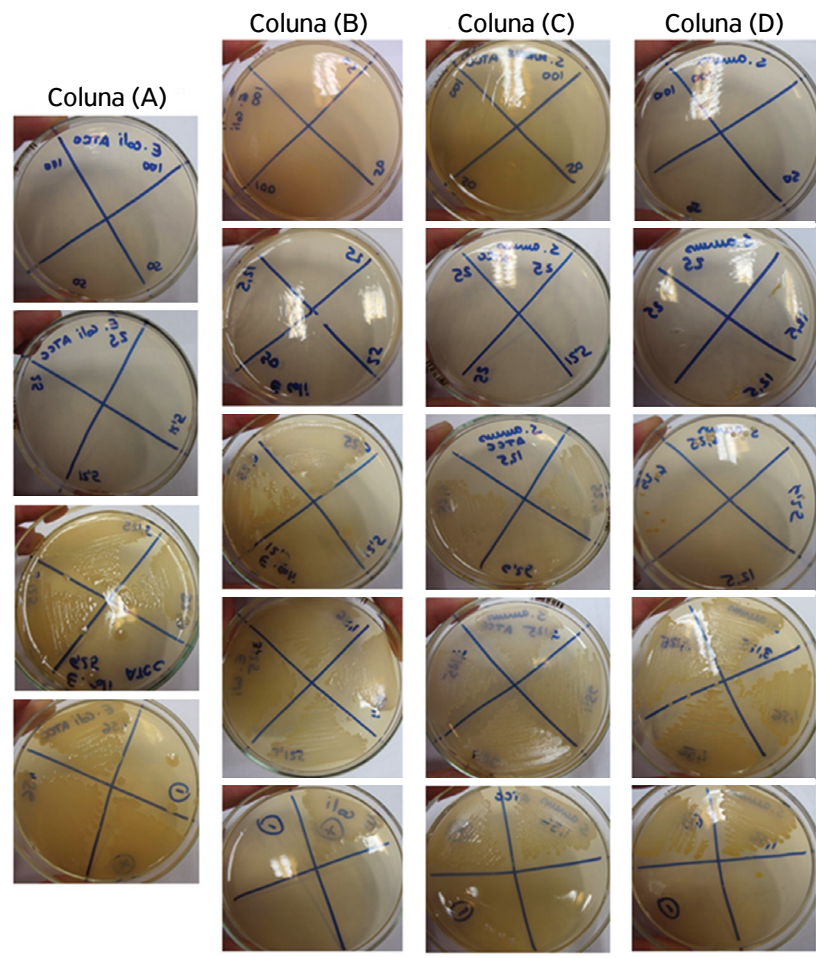

Figura 1. Placas semeadas com as culturas submetidas à ação das concentrações de 100 a $1,56 \mu \mathrm{L} / \mathrm{mL}$ do óleo essencial de orégano, além dos controles positivo e negativo. (A) E. coli (ATCC 25922), (B) E. coli clínica, (C) S. aureus (ATCC 25923) e (D) S. aureus clínica.
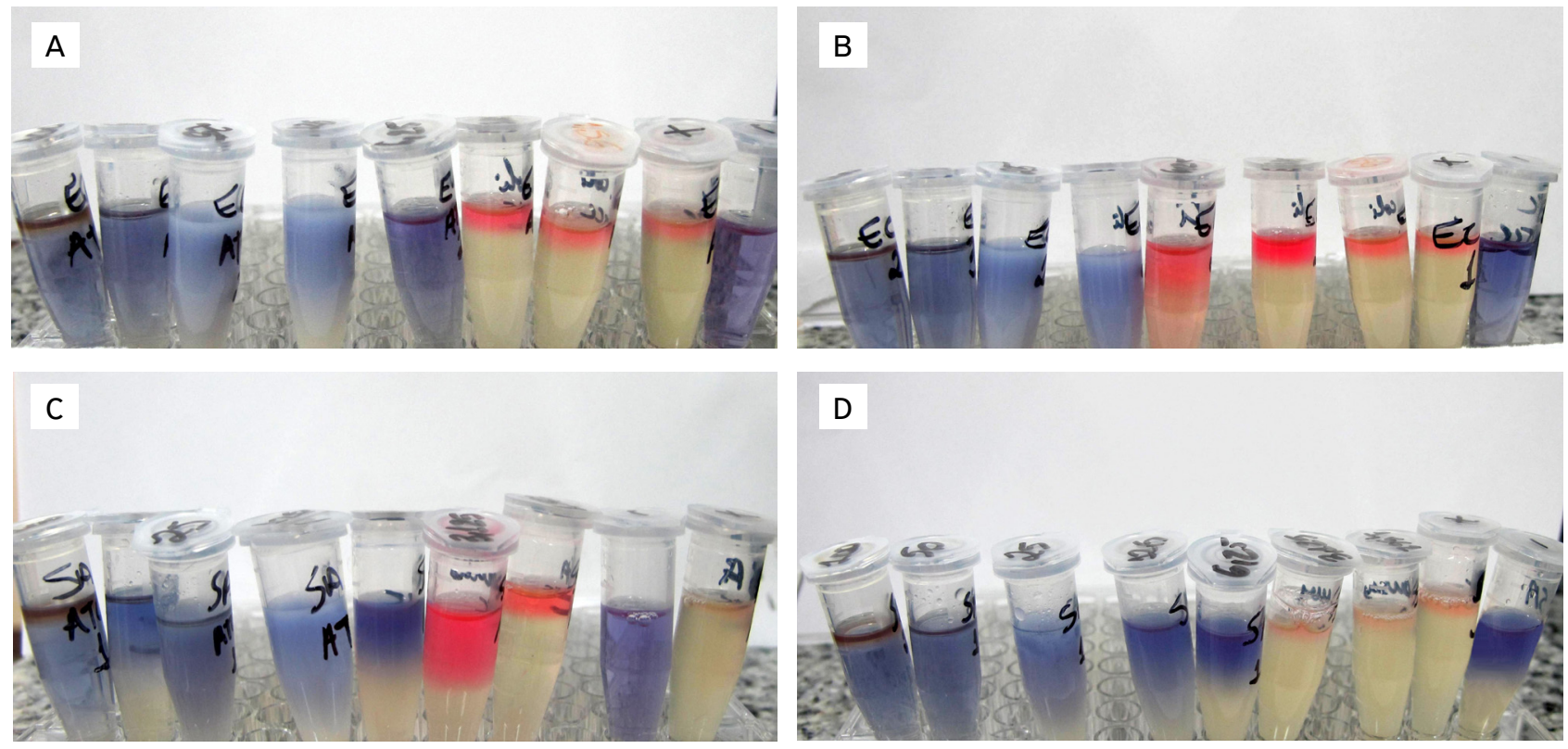

Figura 2. Microtubos usados no experimento de macrodiluição após uma hora da adição de resazurina sódica. (A) E. coli ATCC, (B) E. coli clínica, (C) S. aureus ATCC e (D) S. aureus clínica. 
evidencia a presença de crescimento microbiano, sendo um indicador de oxidorredução, em que a coloração azul indica ausência de crescimento microbiano, enquanto a cor vermelha representa a presença de células viáveis em crescimento; dessa maneira, é possível determinar a menor concentração de óleo capaz de inibir o crescimento dos micro-organimos utilizados (BONAN et al., 2010).

A Fig. 2 demonstra, por meio da coloração, o efeito bacteriostático do antimicrobiano diante de cepas distintas. Os dados da Tabela 1 sumarizam os resultados da leitura da macrodiluição, evidenciando, assim, o poder bactericida e bacteriostático que o óleo desempenha. Pode-se observar que, para a amostra padrão de E. coli (ATCC 25922), a concentração inibitória mínima (CIM) do óleo essencial utilizado foi de $6,25 \mu \mathrm{L} / \mathrm{mL}$ e a concentraçáo bactericida mínima (CBM), de $12,5 \mu \mathrm{L} / \mathrm{mL}$, ao passo que, para a amostra clínica, os valores foram, respectivamente, 12,5 e $25 \mu \mathrm{L} / \mathrm{mL}$.

Já para a amostra padrão de $S$. aureus (ATCC 25923), a CIM e a CBM do óleo essencial foram de $12,5 \mu \mathrm{L} / \mathrm{mL}$, enquanto para a amostra clínica, 6,25 e $25 \mu \mathrm{L} / \mathrm{mL}$, respectivamente.

$\mathrm{Na}$ segunda etapa do estudo foi realizada a detecção da atividade antimicrobiana pela técnica da microdiluição apenas para as amostras padrão de cada espécie bacteriana.

A Fig. 3 mostra a placa teste após adição de resazurina sódica às culturas bacterianas, evidenciando que, à medida que a concentraçấo de óleo essencial aumenta, a coloração assume tonalidades mais escuras, o que indica inibição do crescimento bacteriano. A Tabela 2 mostra os resultados do experimento

Tabela 1. Resultados do teste da atividade antimicrobiana do óleo essencial de orégano pela técnica de macrodiluição sobre amostras padrão (ATCC 25922 e 25923 ) e clínicas de Escherichia coli e Staphylococcus aureus.

\begin{tabular}{lcccccccc}
\multirow{2}{*}{ [ ] do óleo } & \multicolumn{2}{c}{ E. coli - ATCC } & \multicolumn{2}{c}{ E. coli - clínica } & \multicolumn{2}{c}{ S. aureus - ATCC } & \multicolumn{2}{c}{ S. aureus - clínica } \\
\cline { 2 - 10 } & Tubos & Placas & Tubos & Placas & Tubos & Placas & Tubos & Placas \\
\hline $100 \mu \mathrm{L} / \mathrm{mL}$ & A/A & $-/-$ & A/A & $-/-$ & A/A & $-/-$ & A/A & $-/-$ \\
\hline $50 \mu \mathrm{L} / \mathrm{mL}$ & A/A & $-/-$ & A/A & $-/-$ & A/A & $-/-$ & A/A & $-/-$ \\
\hline $25 \mu \mathrm{L} / \mathrm{mL}$ & A/A & $-/-$ & A/A & $-/-$ & A/A & $-/-$ & A/A & $-/-$ \\
\hline $12,5 \mu \mathrm{L} / \mathrm{mL}$ & A/A & $-/-$ & A/A & $+/+$ & A/A & $-/-$ & A/A & $+/+$ \\
\hline $6,25 \mu \mathrm{L} / \mathrm{mL}$ & A/A & $+/+$ & $\mathrm{V} / \mathrm{V}$ & $+/+$ & A/A & $+/+$ & $\mathrm{A} / \mathrm{A}$ & $+/+$ \\
\hline $3,125 \mu \mathrm{L} / \mathrm{mL}$ & $\mathrm{V} / \mathrm{V}$ & $+/+$ & $\mathrm{V} / \mathrm{V}$ & $+/+$ & $\mathrm{V} / \mathrm{V}$ & $+/+$ & $\mathrm{V} / \mathrm{V}$ & $+/+$ \\
\hline $1,56 \mu \mathrm{L} / \mathrm{mL}$ & $\mathrm{V} / \mathrm{V}$ & $+/+$ & $\mathrm{V} / \mathrm{V}$ & $+/+$ & $\mathrm{V} / \mathrm{V}$ & $+/+$ & $\mathrm{V} / \mathrm{V}$ & $+/+$ \\
\hline $\mathrm{C}+$ & $\mathrm{V}$ & + & $\mathrm{V}$ & + & $\mathrm{V}$ & + & $\mathrm{V}$ & + \\
\hline $\mathrm{C}-$ & A & + & A & - & A & + & $\mathrm{A}$ & +
\end{tabular}

[ ]: "concentração" do óleo; ATCC: American Type Culture Collection; A: azul - não há atividade microbiana; V: vermelho - há atividade microbiana; +: presença de colônia; -: ausência de colônia.

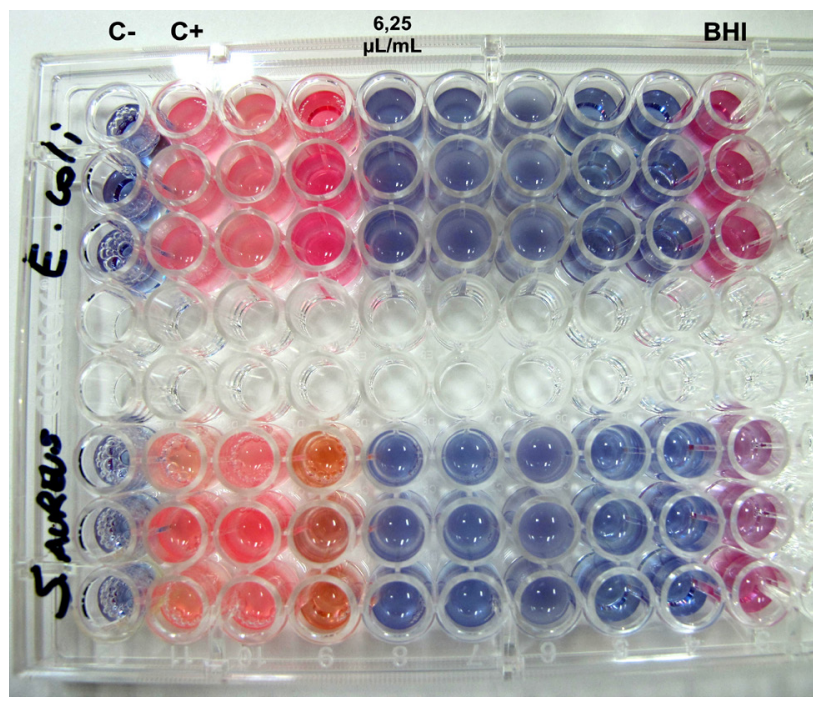

Figura 3. Placa de 96 poços utilizada no experimento de microdiluição após adição de resazurina para a determinação da concentração inibitória mínima do 0 . vulgare sobre as cepas E. coli (ATCC 25922) e S. aureus (ATCC 25923).
Tabela 2. Resultados do teste da atividade antimicrobiana do óleo essencial de orégano em diferentes concentrações pela técnica de microdiluição sobre amostras padrão (ATCC 25922 e 25923) de Escherichia coli e Staphylococcus aureus.

\begin{tabular}{lcccccc} 
& \multicolumn{3}{c}{ E. coli-ATCC } & \multicolumn{3}{c}{ S. aureus - ATCC } \\
\cline { 2 - 7 } [ ] do óleo & I & II & III & I & II & III \\
\hline C- & A & A & A & A & A & A \\
\hline C+ & V & V & V & V & V & V \\
\hline $1,56 \mu \mathrm{L} / \mathrm{mL}$ & V & V & V & V & V & V \\
\hline $3,125 \mu \mathrm{L} / \mathrm{mL}$ & V & V & V & V & V & V \\
\hline $6,25 \mu \mathrm{L} / \mathrm{mL}$ & A & A & A & A & A & A \\
\hline $12,5 \mu \mathrm{L} / \mathrm{mL}$ & A & A & A & A & A & A \\
\hline $25 \mu \mathrm{L} / \mathrm{mL}$ & A & A & A & A & A & A \\
\hline $50 \mu \mathrm{L} / \mathrm{mL}$ & A & A & A & A & A & A \\
\hline $100 \mu \mathrm{L} / \mathrm{mL}$ & A & A & A & A & A & A \\
\hline BHI & V & V & V & V & V & V \\
\hline
\end{tabular}

[ ]: "concentração" do óleo; ATCC: American Type Culture Collection; A: azul - não há atividade microbiana; V: vermelho - há atividade microbiana; +: presença de colônia; -: ausência de colônia. 
de microdiluição após adição de resazurina sódica, em que se pode observar que, para as amostras padráo (tanto de E. coli quanto de $S$. aureus), o óleo utilizado apresentou uma CIM de $6,25 \mu \mathrm{L} / \mathrm{mL}$. Os dados também mostram que essa inibição não foi realizada pela adiçâo do Tween 80 ao meio, já que no controle positivo (meio de cultura + Tween 80 + inóculo bacteriano) houve crescimento microbiano. SeRPA et al. (2007) relataram que o óleo essencial de orégano a uma concentração de $3,125 \mu \mathrm{L} / \mathrm{mL}$ foi capaz de inibir cepas de E. coli e $S$. aureus. BURT; ReIDERs (2003) relataram que a concentração de 0,625 $\mu \mathrm{L} / \mathrm{mL}$ em contato com a $E$. coli $\mathrm{O} 157: \mathrm{H} 7$ por um minuto seria suficiente para inviabilizar o crescimento da cepa. Já SAGDiç (2003) avaliou a açáo inibitória do óleo essencial de orégano sobre bactérias patogênicas e observou sua efetividade na inibição de $S$. aureus, E. coli e Yersinia enterocolítica. O óleo essencial nas concentraçôes de 1 e $2,5 \mu \mathrm{L} / \mathrm{mL}$ foi bacteriostático, enquanto nas concentrações de 5 e $7,5 \mu \mathrm{L} / \mathrm{mL}$ teve ação bactericida.

Alexopoulos et al. (2011) relataram que o óleo essencial de $O$. vulgare mostrou-se ativo contra cepas de $S$. aureus, quando testadas por difusão em disco e diluição em caldo, sendo que a diluição exigiu valores maiores de CIM (> $256 \mathrm{mg} / \mathrm{L}$ ). Santos et al. (2011), utilizando a mesma técnica de difusão em disco, verificaram que a CIM do óleo essencial de orégano diante de $E$. coli e $S$. aureus foi, respectivamente, de 0,5 e $0,25 \mathrm{~mL} / \mathrm{mL}$.

No presente estudo, a análise da efetividade do óleo essencial comercial de orégano $(O$. vulgare $)$ na inibição de micro-organismos patogênicos $E$. coli e $S$. aureus demonstrou atividade antimicrobiana efetiva (bactericida e bacteriostática) para as cepas padrôes em concentraçóes acima ou iguais a $12,5 \mu \mathrm{L} / \mathrm{mL}$ e nas cepas clínicas acima ou iguais a $25 \mu \mathrm{L} / \mathrm{mL}$.

Essa diferença na atividade antimicrobiana entre os diferentes estudos pode estar relacionada às cepas bacterianas utilizadas, já que cepas da mesma espécie podem apresentar resistência diferenciada. Além disso, deve-se considerar os diferentes óleos essenciais utilizados, visto que diferentes concentraçôes dos princípios ativos podem estar presentes, uma vez que cada componente no orégano colhido pode variar em relação à época do ano (SARTORATTO et al., 2004), além dos diferentes fatores geográficos que influenciam na composiçấo, qualidade e quantidade de óleo essencial (Oliveira et al., 2008).

\section{CONCLUSÃO}

Os resultados obtidos neste estudo indicam que o óleo comercial de orégano utilizado teve atividade antimicrobiana em diferentes amostras bacterianas, Gram-positivas e negativas, porém tal ação nấo foi igual para as diferentes amostras testadas, tanto entre espécies quanto dentre amostras da mesma espécie. Além disso, como esperado, foi possível observar que para haver a ação bactericida a concentraçáo do óleo necessária foi maior do que para atividade bacteriostática.

Porém, para que o orégano possa ser utilizado como substância antimicrobiana (fármaco natural), fatores abióticos relativos ao óleo, aliados a uma grande diversidade de amostras bacterianas existentes, devem ser considerados para que se estabeleçam as concentraçôes antimicrobianas e citotóxicas da espécie.

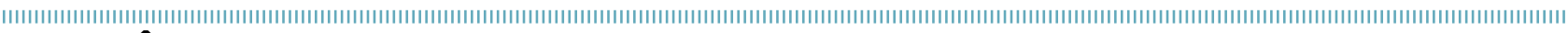
REFERÊNCIAS

ALEXOPOULOS, A.; KIMBARIS, A.C.; PLESSAS, S.; MANTZOURANI, I.; THEODORIDOU, I.; STAYROPOULOU, E.; POLISSIOU, M.G.; BEZIRTZOGLOU, E. Antibacterial activities of essential oils from eight Greek aromatic plants against clinical isolates of Staphylococcus aureus. Anaerobe, v.17, n.6, p.399-402, 2011.

AMERICAN TYPE CULTURE COLLECTION - ATCC. The Global Bioresource Center. Disponível em: <http://www.atcc.org/>. Acesso em: 15 jun. 2011.

BONAN, P.R.F.; CACIQUE, A.P.; BOTELHO, B.L.; FARIA, A.K.S.; NOBRE, S.A.M.; PRATA, E.R.B.A. Avaliação do estresse térmico de Candida albicans utilizando microplacas e resazurina como indicador de oxidação. In: FÓRUM - DESENVOLVIMENTO REGIONAL: COMPROMISSO DA UNIMONTES, 4. Montes Claros: Unimontes, 2010.

BRESOLIN, B.M.Z.; DALL'STELLA, J.K.; DA SILVA, S.E.F. Pesquisa sobre a bactéria Staphylococcus aureus na mucosa nasal e mãos de manipuladores de alimentos em Curitiba/ Paraná/Brasil. Estudos de Biologia, v.27, n.59, p. 27-32, 2005.
BURT, S.A.; REINDERS, R.D. Antimicrobial activity of selected plant essential oils against Escherichia coli 0157:H7. Letters in Applied Microbiology, v.36, p.162-167, 2003.

CUNHA, M.A. Métodos de detecção de microrganismos indicadores. Saúde \& Ambiente em Revista Duque de Caxias, v.1, n. 1, p.09-13, 2006.

FIO, F.S.D.; MATTOS FILHO, T.R.; GROPPO, F.C. Resistência bacteriana. Revista Brasileira de Medicina, v.57, n.10, 2000. Disponível em: <http://www.moreirajr.com.br/revistas. asp?fase=r003\&id_materia=70>. Acesso em: 10 abr. 2011.

KOKKINI, S.; KAROUSOU, R.; DARDIOTI, A.; KRIGAS, N.; LANARAS, T. Autumn essential oils of Greek oregano. Phytochemistry, v.44, n.5, p.883-886, 1997.

LASZLO - Aromaterapia Ltda. Certificado de Analise Química (Cromatografia Gasosa do Óleo Essencial de Orégano). Disponível em: <www.laszlo.ind.br>. Acesso em: 13 mar. 2011. 
LEVY, C.E.; VON NOWAKONSKI, A.; MENDES, C.M.F.; OPLUSTIL, C.; ZOCCOLI, C.M.; MAFFEI, C.M.L.; MAMIZUKA, E.M.; CAVASSIN, E.D.; ROSSI, F.; MIMICA, I.; PETRIDIS, H.; MIMICA, L.M.J.; MELHEM, M.S.C.; LOPES, M.C.G.; MARTINO, M.D.V.; LINCOPAN, N.; SILVA, R.A.M. Manual de Microbiologia Clínica para o Controle de Infecção em Serviços de Saúde. In: Modulo I - Principais Síndromes Infecciosas. $1^{\text {a }}$ ed. Brasília: Agência Nacional de Vigilância Sanitária, 2004.

MAGALHÃES, C.F. Efeito de extratos e frações de Piper aduncum sobre o crescimento e metabolismo dos Streptococcus mutans e Streptococcus sanguis. Dissertação (Mestrado - Imunopatologia das Doenças Infecciosas e Parasitárias) - Universidade Vale do Rio Doce, Governador Valadares, 2010.

NATIONAL COMMITTEE FOR CLINICAL LABORATORY STANDARDS - NCCLS. Metodologia dos Testes de Sensibilidade a Agentes Antimicrobianos por Diluição para Bactéria de Crescimento Aeróbico: Norma Aprovada. 6. ed. Norma M7-A6 do NCCLS, v.22, n.2, p. 14-19, 2003.

OLIVEIRA, D.H.; FARIAS, A.M.; CLEFF, M.B.; MEIRELES, M.C.A.; RODRIGUES, M.R.A. Caracterização química do óleo essencial de Origanum vulgare: análise da relação timol/carvacrol. In: CONGRESSO DE INICIAÇÃO CIENTÍFICA, 17., Pelotas, 2008. Pelotas: UFPel.

OLIVEIRA, F.Q.; GOBIRA, B.; GUIMARÃES, C.; BATISTA, J.; BARRETO, M.; SOUZA, M. Espécies vegetais indicadas na odontologia. Revista Brasileira de Farmacognosia, v.17, n.3, p.466-476, 2007.

PRĖRE, M.F.; FAYET, O. A new genetic test for the rapid identification of shigatoxines producing (STEC), enteropathogenic (EPEC) E. coli isolates from children. Pathologie Biologie, Paris, v.53, p.466-469, 2005.

SAGDIÇ, O. Sensitivity of four pathogenic bacteria to Turkish thyme and oregano hydrosols. Lebensmittel-Wissenschaft $\odot$ Technologie, v.36, n.5, p.467-473, 2003.

SANTOS, A.S.; ALVES, S.D.M.; FIGUEIREDO, F.J.C.; ROCHA NETO, O.G. Descrição de sistema e de métodos de extração de óleos essenciais e determinação de umidade de biomassa em laboratório. Embrapa Amazônia Oriental. Comunicado Técnico 99 , p. 1-6, 2004.

SANTOS, J.C.; CARVALHO FILHO, C.D.; BARROS, T.F.; GUIMARÃES, A.G. Atividade antimicrobiana in vitro dos óleos essenciais de orégano, alho, cravo e limão sobre bactérias patogênicas isoladas de vôngole. Semina: Ciências Agrárias, Londrina, v.32, n.4, p.1557-1564, 2011.

SARTORATTO, A.; MACHADO, A.L.M.; DELARMELINA, C.; FIGUEIRA, G.M.; DUARTE, M.C.T.; REHDER, V.L.G. Composition and antimicrobial activity of essential oils from aromatic plants used in Brazil. Brazilian Journal of Microbiology, v.35, n.4, p.275280, 2004.

SERPA, R.; LIMA, M.C.; ZARINA, S.; KRAUSE, L.C.; RODRIGUES, M.R.A.; RIBEIRO, G.A. Perfil Químico e Avaliação da Atividade Antibacteriana do Óleo Essencial do "Orégano" - Origanum vulgare linnaeus. In: CONGRESSO DE INICIAÇÃO CIENTÍFICA, 16.; ENCONTRO DE PÓS-GRADUAÇÃO, 9. Anais... Pelotas: UFPel, 2007.

SHELTON, D.R.; KARNS, J.S.; HIGGINS, J.A.; VAN KESSEL, J.A.S.; PERDUE, M.L.; BELT, K.T.; RUSSELL-ANELLI, J.; DEBROY, C. Impact of microbial diversity on rapid detection of enterohemorrhagic Escherichia coli in surface waters. FEMS Microbiology Letters, v.261, p.95-101, 2006.

SILVA, J.P.L.; DUARTE-ALMEIDA, J.M.; PEREZ, D.V.; FRANCO, B.D.G.M. Óleo essencial de orégano: interferência da composição química na atividade frente a Salmonella enteritidis. Ciência e Tecnologia de Alimentos, Campinas, v.30, p.136-141, 2010. Suplemento 1.

SOUZA, E.L. Potencial antimicrobiano do óleo essencial de orégano (Origanum vulgare L.): Uma abordagem para uso em sistemas de conservação de alimentos. Tese (Doutorado - Nutrição) Universidade Federal de Pernambuco, Recife, 2006.

VIEIRA, F.F.; AGOSTINI, J.S. Prevalence and profile of Staphylococcus aureus infections caused by isolated in a public Hospital of Dourados-MS. In: INTERNATIONAL CONGRESS OF PHARMACEUTICAL SCIENCES, 8. Anais... Ribeirão Preto: CIFARP, 2011.

WORLD HEALTH ORGANIZATION - WHO. Global Antimicrobial Resistance Surveillance System: Manual for Early Implementation. Geneva: WHO, 2015. 36p.

YIN, Q.H.; YAN, F.X.; ZU, X.Y.; WU, X.P.; LIAO, M.C.; DENG, S.W.; YIN, L.L.; ZHUANG, Y.Z. Anti-proliferative and pro-apoptotic effect of carvacrol on human hepatocellular carcinoma cell line HepG-2. Cytotechnology, v.64, n.1, p.43-51, 2012. 